\title{
O Serviço de Informações e a cultura do segredo*
}

\section{The Secret Service and the culture of secrecy}

\author{
SUZELEY KALIL MATHIAS \\ FABIANA DE OLIVEIRA ANDRADE \\ Faculdade de Ciências Humanas e Sociais \\ Universidade Estadual Paulista - UNESP, Campus de Franca \\ Av. Eufrásia Monteiro Petráglia, 900 \\ Bairro: Jd. Dr. Antonio Petráglia \\ CEP 14409-160 - Franca - SP \\ suzeley.kama@gmail.com \\ oliveirafabiana410@hotmail.com
}

RESUMO Neste texto revisitamos a formação dos serviços de inteligência no Brasil e sua adaptação à cultura do segredo. Também avaliamos como a existência de serviços de inteligência no interior das forças armadas modificaram a estratégia de atuação castrense no âmbito interno, utilizando como exemplo a campanha Marajoara, terceira empreitada militar na guerrilha do Araguaia.

Palavras-chave inteligência, segredo, forças armadas, Brasil

ABSTRACT In this paper we revisit the formation of intelligence services in Brazil and its adaptation to the culture of secrecy. We also evaluate how the existence of intelligence services within the armed forces have changed the strategy of action in the framework military built, using the example of the Marajoara campaign in Araguaia guerrilla.

Keywords intelligence, secrecy, armed forces, Brazil

* Artigo recebido em 20/08/2012. Autor convidado. 


\section{Introdução}

Diferentes formuladores teóricos que pensam o conceito de Estado defendem a necessidade da existência de segredos governamentais e de serviços de inteligência como recurso legítimo para a sua salvaguarda. Norberto Bobbio, por exemplo, trata os mistérios do Estado em sua obra $O$ Futuro da Democracia. Nela o autor nos apresenta o conceito de "criptogoverno" como o "conjunto de ações realizadas por forças políticas eversivas que agem na sombra em uma articulação com os serviços secretos". ${ }^{1}$

Já Hanna Arendt em A Mentira na Política, apresenta o sigilo como inerente aos assuntos do Estado:

Sigilo - diplomaticamente chamado de 'discrição' e de arcana imperii (os mistérios do governo) - e embuste, ou seja, a falsidade deliberada e a mentira descarada, são usadas como meios legítimos para alcançar fins políticos desde os primórdios da história documentada. ${ }^{2}$

O Brasil, tendo formado seu Estado no esteio de uma já considerável burocracia, herdou a valorização, quiçá exacerbada, da organização de serviços de inteligência (de agora em diante SI) que primam pela não transparência, isto é, tais serviços funcionavam, e muitas vezes ainda funcionam como clandestinos no interior do Estado, e realizam seu trabalho buscando, no próprio país, as ameaças à estabilidade política. No entanto, apenas serviços muito específicos e guiados por uma legislação que prime pela transparência e atentos aos princípios de proporcionalidade, podem se ocupar das ameaças internas à Nação. Com isto queremos dizer que, apesar de saber das ameaças que a presença destas instituições, atuando sem controle, configuram para o estado democrático, acreditamos que os $\mathrm{SI}$, se subordinados estritamente ao Judiciário e sem nenhuma relação com a defesa, podem incluir entre seus afazeres, a responsabilidade pela segurança interna.

Segundo artigo recentemente publicado no jornal O Estado de São Paulo, um dos poucos assuntos que une partidos de oposição e situação refere-se às medidas a serem tomadas contra o vazamento de informações relativas a assuntos atinentes à segurança nacional, pois a banalização de tais dados pela imprensa pode redundar em problemas para a manutenção do monopólio da força nas mãos do Estado. Diferente do que se possa imaginar, o país objeto desta reportagem não era o Brasil, mas sim os EUA, cujos parlamentares fo-

BOBBIO, Norberto, MATEUCCI, Nicolas e PASQUINO, Giafranco. Dicionário de Política. Brasília: Editora Universidade de Brasília, 1986, p. 103.

2 ARENDT, Hannah. A condição humana. Rio de Janeiro: Editora Forense Universitária, 2004, p. 15. 
ram além da simples reclamação conjunta e solicitaram ao Poder Executivo medidas mais duras no controle da divulgação de material de inteligência, conforme nos informa Scott Shane. ${ }^{3}$

O exemplo reforça importante análise de Priscila Brandão a respeito do funcionamento dos SI nas democracias: um dos principais problemas a serem enfrentados é justamente como controlar serviços do Estado que têm no segredo um dos seus pilares básicos. ${ }^{4}$ Desde a emergência do discurso iluminista são defendidos como valores fundamentais para a consolidação das instituições democráticas, a visibilidade do Estado, a transparência do poder, e o acesso às informações governamentais. ${ }^{5}$

No entanto nossa intenção aqui não é discutir a necessidade do desenvolvimento de SI no interior dos Estados ou seu controle e transparência sob regimes democráticos. 0 que se pretende é apresentar a hipótese de que os serviços de informações e inteligência no Brasil desenvolvidos no pós Segunda Guerra Mundial alimentavam e exacerbavam a cultura do segredo, postura própria de burocracias de viés autoritário.

De início apresentaremos, brevemente, as origens do serviço de informações no Brasil, apontando alguns dados sobre o Serviço Nacional de Informações (SNI) criado em 1964 e sua evolução sob o regime burocrático-autoritário que então vigorava no Brasil. Na segunda parte percorreremos um pouco da história da formação e desenvolvimento da Guerrilha do Araguaia. Por fim, na terceira parte, ao elaborarmos uma análise sobre a participação do SNI na Guerrilha do Araguaia, verificaremos a veracidade de nossa hipótese no que tange à exacerbação do segredo no interior do próprio governo, contribuindo para o esclarecimento sobre um dos períodos mais cinzentos de nossa história, na medida em que nosso estudo recairá sobre a análise da "Operação Marajoara", conhecida também como "a Terceira Campanha do Araguaia". Nas palavras de Taís Morais e Eumano Silva na obra Operação Araguaia:

O governo militar fez todo o esforço possível para apagar a Guerrilha do Araguaia da História [...] [entretanto] os governos militares fracassaram na tentativa de jogar a Guerrilha do Araguaia no esquecimento. Depoimentos de sobreviventes do conflito e documentos produzidos pelos serviços secretos do governo preservaram por mais de três décadas a memória de um dos mais chocantes episódios da História do Brasil. ${ }^{6}$

O Estado de S. Paulo, 10/06/2012, p. A-18.

4 BRANDÃO, Priscila C. Serviços secretos e democracia no Cone Sul: premissas para uma convivência legítima, eficiente e profissional. Niterói: Editora Impetus, 2010, p.3.

5 BOBBIO, Norberto, MATEUCCI, Nicolas e PASQUINO, Giafranco. Dicionário de Política, p.103.

6 MORAIS, Taís e SILVA, Eumano. Operação Araguaia: os arquivos secretos da guerrilha. São Paulo: Geração Editorial, 2011, p. 13-14. 


\section{Alguns aspectos da Informação no Brasil}

É desnecessário apresentar aqui toda a origem e desenvolvimento dos serviços de inteligência brasileiros ao longo de sua história. Importa-nos apresentar, ainda que de forma sucinta, o processo de criação do serviço de inteligência estatal que redundaria na criação do Serviço Nacional de Informações (SNI), responsável pelo desencadeamento das operações paramilitares empreendidas no Araguaia, fenômeno o qual desejamos aqui avaliar.

A Segunda Guerra Mundial e a participação brasileira por meio da Força Expedicionária Brasileira trouxeram novos horizontes para o país, especialmente para as Forças Armadas. Em termos comparativos, nossos combatentes perceberam não apenas a defasagem tecnológica militar brasileira, mas principalmente estrutural, organizacional, e doutrinária. ${ }^{7}$ Uma vez regressados ao país suas ações passaram, então, a ter como objetivo principal se assemelhar às suas congêneres norte-americanas. Em termos práticos, a nova percepção das Forças Armadas implicou, de imediato, a queda da ditadura varguista e da ideologia nacionalista que a sustentava.

Com a nova conjuntura internacional, forjada na liderança irreconciliável entre os pró-soviéticos e os pró-estadunidenses, o Brasil situou-se sob a égide destes últimos. No âmbito do assunto que move as preocupações deste texto, o Conselho de Segurança Nacional sofreu pequenas reformas, tornando mais explicita sua responsabilidade com as questões internas, e foi criado o SFICI - Serviço Federal de Informações e Contra Informações, por meio do Decreto-lei 9.775-A/1946.

No entanto o SFICI foi implementado apenas no ano de 1956, já durante o governo democrático de Juscelino Kubistchek, e tratou-se do principal órgão civil de informações do país até 1964, o primeiro que se encarregou explicitamente da atividade de contraespionagem e contrainformações. A introdução de temas mais atinentes à segurança interna brasileira do que à defesa durante o governo JK influenciou sua organização, cujo modelo também foi impactado por uma maior presença norte-americana, a partir da criação da Escola das Américas, no Panamá. ${ }^{8}$ Aliás, a reforma da legislação que conduziu à sua implantação ocorreu justamente em função da influência norte-americana, ${ }^{9}$ na medida em que pretendia-se extin-

7 OLIVEIRA, Eliezer Rizzo. As forças armadas: política e ideologia no Brasil (1964-1969). Petrópolis: Vozes, 1976, p.55.

8 Manual de Contra inteligência (1963), Escuela de las Américas. Disponível em www.soaw.org/new/article. php?id=98, acesso em 20 ago. 2012.

9 A montagem do Sfici contou com apoio logístico e financeiro da CIA e FBI. Grande parte da influencia americana foi devida à presença de seu Secretario de Estado, John Foster Dulles, e pelos militares da Escola Superior de Guerra. 
guir as deficiências estruturais do SFICI, que prejudicavam o combate ao "comunismo". ${ }^{10}$

Com o Decreto 45.040/1958, que estruturou o funcionamento SFICI, estabeleceu-se que sua Secretaria Geral responsabilizar-se-ia pela elaboração da estratégia nacional e, consequentemente, pelo entendimento das matérias atinentes à segurança nacional, bem como pela orientação geral dos órgãos e pessoal responsáveis pela manutenção da segurança nacional. ${ }^{11} \mathrm{~A}$ primeira missão de "guerra interna" atribuída ao SFICI ocorreu em 1959, após a Revolução Cubana, pois temiam mobilizações da esquerda brasileira. Cuba era conhecida como incentivadora do alastramento da revolução e assim deveriam, portanto, identificar e neutralizar sua infiltração e os 'inimigos', cujo primeiro alvo foi o movimento estudantil. ${ }^{12}$

Como efeito dessas operações, alcançou-se uma relativa profissionalização de agentes e padronização de métodos e procedimentos do $\mathrm{SFICI}$, a exemplo da publicação do Glossário de Informações (1960) que, segundo Figueiredo, tinha por objetivo padronizar o jargão dos agentes, de modo a evitar mal entendidos. ${ }^{13}$ Em seguida foram publicados Noções sobre operações clandestinas, bem como Instrução particular que regula o funcionamento da Subseção de Operações (SSOP), todos datados de $1960 .{ }^{14} \mathrm{Em}$ relação à eficácia do $\mathrm{SFICl}$, existem várias análises que apontam sua incipiência e ineficiência, ainda que as opiniões sobre o tema sejam marcadas pela divergência. ${ }^{15} \mathrm{O}$ fato é que, por sua subordinação burocrática transformá-lo em um setor meramente consultivo, sem poderes reais para desenvolver sua autonomia burocrática, foi considerado pelos condutores do golpe de 1964, como pouco funcional. ${ }^{16}$ Por isso mesmo, sequer cogitaram sua reforma e, ao contrário, resolveram pela completa reestruturação do órgão, instituindo o Serviço Nacional de Informações (SNI).

O coronel Golbery do Couto e Silva, auxiliar do Marechal Castelo Branco, alçado à Presidência da República com o apoio do Congresso ainda em abril

10 Para um entendimento sobre as questões que permearam a extinção do SFICI ver: ANTUNES, Priscila Brandão. SNI e ABIN: uma leitura da atuação dos serviços secretos brasileiros ao longo do século XX. Rio de Janeiro: Fundação Getulio Vargas, 2002. p.46-54.

11 ANTUNES, Priscila Brandão. SNI e ABIN, p.49.

12 MARTINS FILHO, João Roberto. Movimento estudantil e a ditadura militar: 1964-1968. Campinas: Papirus, 1987, p.188-191.

13 FIGUEIREDO, Lucas. Ministério do silêncio: a história do serviço secreto de Washington Luis a Lula (19272005). São Paulo: Record, 2005, p.85.

14 FIGUEIREDO, Lucas. Ministério do silêncio, p.85.

15 Para uma análise sobre as divergências em torno do processo de institucionalização do SFICI ver: ANTUNES, Priscila Brandão. SNI e ABIN, p.46-54.

16 FIGUEIREDO, Lucas. Ministério do silêncio, considera entre as deficiências do SFICI a ausência de acesso direto ao presidente da Republica, de autonomia financeira e de uma agencia regional em Brasília. 
de 1964, propôs ao presidente que criasse um novo sistema de informações, baseado na organização do antigo $\mathrm{SFICl}$, mas com características operativas para que, assim, pudesse auxiliar o governo e, através dele, possibilitar à nação alcançar seus "Objetivos Nacionais", ao mesmo tempo que superava os óbices que se interpunham à realização dos mesmos objetivos. ${ }^{17}$ Nas palavras de Golbery do Couto e Silva, idealizador e primeiro chefe do SNI, haveria a necessidade, a título de preservação do governo, de um "serviço de informações, centralizado, bem dotado de meios e recursos, valendo-se de agentes e órgãos de busca de toda espécie". ${ }^{18}$

A constituição de um novo sistema de informações aconteceu em uma conjuntura que não era ideologicamente homogênea, inclusive, nem no interior da caserna. Grosso modo, as principais correntes militares daquele período poderiam ser reduzidas a duas vertentes extremas, uma conhecida por "linha dura", e outra por "sorbonistas", "legalistas", ou "castelistas". ${ }^{19}$ Os primeiros fundamentavam sua ação na certeza da distinção entre mundo da caserna e mundo civil, tendo no preparo para a defesa a justificativa da ação. Já os sorbonistas eram constituídos pelos intelectuais, por aqueles que se preocupavam não apenas com a sua formação, mas com a condução política da guerra. 0 que une as vertentes está, nas palavras de Gorender, “[n]a obsessão anticomunista, [n]a obsessão da imposição à sociedade civil da disciplina e hierarquia características do ethos militar, [...] obsessão da construção de uma grande nação". ${ }^{20}$ Tais ideias encontraram campo fértil na vigência da lógica da Guerra Fria, da influência política norte-americana, da tradição legalista, ${ }^{21}$ e do fortalecimento da ideologia de segurança nacional que se conhece a partir de 1964.

Logo após ser nomeado para a chefia do SNI no dia 25 de junho de 1964, Golbery recorreu ao auxilio estadunidense para a montagem do novo órgão.

17 Para maiores informações sobre objetivos nacionais permanentes e atuais, consulte-se ESG. Manual Básico da ESG. S/1, s/ed., 1978.

18 COUTO E SILVA, Golbery. Planejamento estratégico. São Paulo: Americana, 1979, p.195.

19 Uma imagem expressa essa diferença. Conforme relatam Cruz e Martins, no momento do golpe, enquanto Castelo Branco, representante do sorbonismo, se encontrava em um escritório em Brasília coordenando um conjunto de pessoas que datilografavam freneticamente o que provavelmente seria o projeto do governo, Costa e Silva (linha dura) conduzia a tropa na rua, fazendo proselitismo sobre a "Revolução". CRUZ, Sebastião Velasco e MARTINS, Carlos Estevam. De Castello a Figueiredo: uma incursão na pré-história da "abertura”. In: SORJ, Bernardo e ALMEIDA, Maria Hermínia Tavares de. (orgs.). Sociedade e política no Brasil pós-64. 2. ed. São Paulo: Brasiliense, 1984.

20 Jacob Gorender, Apud FICO, Carlos. Como eles agiam: os subterrâneos da ditadura militar, espionagem e policia política. Rio de Janeiro: Record, 2001, p.13.

21 Chamamos tradição legalista a busca por parte dos militares brasileiros de legitimidade para suas ações por intermédio de normas e regulamentos. Trabalhamos essa idéia particularmente em MATHIAS, Suzeley Kalil e GUZZI, Fabiana de Oliveira. Autonomia na lei: as Forças Armadas nas constituições nacionais. Revista Brasileira de Ciências Sociais, v. 25, p. 41-57, 2010. 
No mesmo ano de sua criação, o Serviço começou a negociar com a CIA (Agência Central de Inteligência), resultando no acordo "Relação de Ligação entre o Serviço Nacional de Informações Brasileiro e o Serviço de Informações Americano".22

Diferentemente da CIA, entretanto, passaram a integrar o SNI membros das Forças Armadas, alguns funcionários do Banco do Brasil, e da administração fazendária, sempre com o predomínio de militares sobre os civis e, entre os militares, o predomínio do Exército. ${ }^{23}$ Apesar disso, parecia que 0 SNI estava longe de sua completa operacionalização, conforme as palavras do jornalista Élio Gaspari:

Só nos primeiros meses de 1965 o Serviço passou a operar suas comunicações através da rede de radio do Planalto. Ainda não completara um ano de vida quando avançou sobre a sala 16 . Iniciava-se a expansão do SNI pela malha modernosa de Brasília, transformando-o numa instituição sociologicamente identificada com a capital, onde se tornou um dos primeiros ramos da burocracia nacional a arraigar-se. ${ }^{24}$

Para alem das controvérsias que envolvem o conceito de Cultura Política, desde Weber os autores reconhecem que sua aplicação acontece na arena pública, que é própria do político. Por definição, portanto, cultura política nega a cultura do segredo. Kant, Madison e de modo geral os pensadores da liberdade ${ }^{25}$ já pregavam a transparência do aparato estatal e da publicidade dos atos do poder. No entanto, como mencionado no início deste texto, desde a formação - para não retroceder às suas formulações ideais - do próprio Estado, se reconhece a necessidade de assuntos relacionados à sua defesa como passíveis de serem mantidas fora do alcance do público.

A formação do militar no Brasil, pelo menos até 1964, se não foi tema restrito às Forças Armadas, fazia parte, em alguma medida, das preocupações da elite do país, que com ela compartilhava a necessidade de pensar um projeto nacional, que conduzisse o país pelo menos ao mesmo grau de desenvolvimento dos EUA. ${ }^{26}$ Obviamente tal desejo não implicava em ultrapassar 0 país do norte, e menos ainda de com ele competir. Ao contrário, talvez pela sua própria formação, esta elite sempre viu o Estado como instrumental para a criação da identidade da nação e, portanto, estava longe de admitir que

22 GASPARI, Élio. A ditadura envergonhada. São Paulo: Companhia das Letras, 2002, p.166.

23 GASPARI, Élio. A ditadura envergonhada, p.159.

24 GASPARI, Élio. A ditadura envergonhada, p.155.

25 GRONDONA, Mariano. Os pensadores da liberdade: de John Locke a Robert Nozick. Brasília: Instituto Tancredo Neves, 2000.

26 COUTO E SILVA, Golbery. Planejamento estratégico, p.29. 
seria a sociedade que se refletiria no Estado, razão pela qual a democracia apresentava-se como discurso, jamais como prática.

Em uma sociedade como a brasileira em meados do século $X X$, não é de se admirar que estaria justamente nas corporações ou instituições fechadas, tais como Forças Armadas e Igreja, uma das principais formas de ascensão social. É o que explica, ao menos em parte, muitos analistas verem as Forças Armadas como representantes da classe média. ${ }^{27}$

0 afastamento paulatino entre caserna e sociedade, e o controle militar sobre as questões palacianas, teve como resultado a exacerbação do que aqui chamamos de "cultura do segredo". Como instrumento de formação do Estado e proteção de seus nacionais, as Forças Armadas são educadas em função de segredos, pois não podem, por exemplo, expor suas armas ou fraquezas aos inimigos, que certamente fariam uso das informações para vencer a batalha.

Essa educação pelo segredo não é, obviamente, privilegio das Forças Armadas e, como bem discutiu Foucault, ${ }^{28}$ é própria das sociedades fechadas que, para o serem, para construir sua identidade, são segregadas do grupo social. Nesse processo, criam-se cidadãos que representam muito mais o sistema social do que as necessidades de suas classes ou estratos. Pode-se dizer que para os militares brasileiros, essa situação sempre foi a realidade corriqueira. ${ }^{29}$

A combinação entre cultura do segredo e atividade de informação, na qual o segredo é inerente, parece ter contribuído bastante, naquela quadra histórica dos anos 1960, para a constituição identitária do SNI. Reforça essa cultura a Lei $n^{\circ} 4.341$, de 13 de junho de 1964, que isentava o SNI de prestar constas, publicar ou divulgar informações sobre sua organização interna, seu quadro de funcionários ou suas regras de atuação.

Não cabe aqui uma discussão exaustiva sobre “cultura do segredo". Quer-se apenas demonstrar que o estrato militar tomou para si a necessidade de definir quais seriam os interesses da sociedade civil. Porém, ao invés de expor para a sociedade quais seriam, guardaram-lhes a sete chaves, alimentando as próprias divergências internas relacionadas à sua divulgação. É por isso que o $\mathrm{SNI}$, ou parte dele, integrou o que veio a ser conhecido como "o sistema". ${ }^{30}$

27 SODRÉ, Nelson Werneck. História militar do Brasil. São Paulo: Expressão Popular, 2010, p.98.

28 FOUCAULT, Michel. A Microfísica do poder. Rio de Janeiro: Graal, 1979.

29 A respeito, vale a pena transcrever o que disse grande especialista na matéria no correr de 2012: "No Brasil, o ensino militar guarda resquícios do século XIX: há oficiais que desde criança não conheceram senão o ambiente militar"; DOMINGOS NETO, Manuel. O apoio do Estado aos estudos da Defesa. Jornal da Ciência - SBPC, 04.06.2012.

30 Conforme Baffa, o "sistema" nasceu a partir da autonomização dos militares que trabalhavam nos vários organismos de inteligência e repressão que, diferentemente de seus pares da caserna, obedeciam a uma cadeia de comando paralela, cujo ápice estava na chefia do SNI, espalhando-se pelos estados brasileiros por meio das diretorias e assessorias de informação. BAFFA, Ayrton. Nos porões do SNI: o retrato do monstro de cabeça oca. Rio de Janeiro: Objetiva, 1989, p.16. 
Paralelamente ao desenvolvimento do regime autoritário, cresceu a oposição a ele, e se nos meios militares não existia homogeneidade, tampouco esta era conhecida entre os que o combatiam. Simplisticamente, a principal divergência entre estes grupos estava na adoção ou não de meios violentos de combate, isto é, na opção, ou não, pela luta armada. ${ }^{31}$

Para a chamada "linha dura", o aumento das contestações e a derrota do governo nas eleições de 1965 representariam a confirmação da fraqueza do governo Castelo Branco em solucionar os problemas causados pelos governos anteriores, especialmente o de João Goulart. Por isso o projeto de Costa e Silva para a Presidência da República incluía recuperar a autoridade do governo, para levar a cabo a operação limpeza, condição necessária para vencer a "subversão" e, portanto, para atingir o desenvolvimento nacional. ${ }^{32}$ Por considerar o SNI despreparado, promoveu-se na segunda gestão dos militares no governo a reestruturação, por parte de cada uma das Forças Armadas, dos seus setores de informações. Os militares no governo entendiam que deveria existir um sistema capaz tanto de produzir o levantamento de informações necessárias à sustentação do regime e administração do governo, quanto para as operações policias e de combate ao "inimigo". Para resolver este impasse, a $2^{\text {a }}$ Seção do Exército - que cuidava das informações - foi reestruturada e, em 2 de maio de 1967, foi criado o Centro de Informações do Exército - CIE, cujo encarregado foi o coronel Adyr Fiuza de Castro. "O surgimento do CIE era apenas o inicio da reformulação no sistema de informações da ditadura. Dali em diante, começaria a ser formada a comunidade de informações, um vigoroso conjunto de órgãos dedicados a identificar e aniquilar os inimigos do governo". ${ }^{33}$

$\mathrm{Na}$ mesma época, por meio das antigas seções de segurança nacional fixadas nos ministérios civis durante o governo Vargas, o SNI se expandia no controle de toda a administração governamental. As chamadas Divisões de Segurança e Informações (DSI), assim nomeadas pelo Decreto $n^{\circ} 60.940$, de julho de 1967, teriam como responsabilidade informar desde a conduta de funcionários e rotina de trabalhos, passando pelas relações entre ministérios e destes com outros órgãos públicos ou privados, até avaliar a conduta de ministros e seus parentes. Ocupadas por militares da ativa e da reserva, divididos os ministérios entre as três Forças, as DSIs adquiriram grande poder, muitas

31 Sem fugir aos objetivos do texto, não temos como trabalhar o tema a contento, razão pela qual resumimos a grande diversidade do movimento de oposição ao regime burocrático-autoritário à adoção ou não de meios violentos de combate ao governo. Para o assunto, consulte-se FICO, Carlos: Versões e controvérsias sobre 1964 e a ditadura militar. Revista Brasileira de História, São Paulo, v.24, n.47, p.29-60, 2004.

32 FIGUEIREDO, Lucas. Ministério do silêncio, p.149.

33 FIGUEIREDO, Lucas. Ministério do silêncio, p.154. 
vezes pondo em xeque a autoridade do próprio ministro. ${ }^{34}$ Também foram criadas as Assessorias de Segurança e Informações - ASI's - que operavam em vários organismos e empresas públicas federais. Assim, cada ministério civil poderia ter uma DSI e várias ASI's. A criação dessas repartições ampliou a rede do SNI e fortaleceu os sistemas de informações do governo militar.

Como defende Carlos Fico, a partir de concepções baseadas na Doutrina de Segurança Nacional - desenvolvida pela Escola Superior de Guerra - ideias como guerra revolucionária e inimigo interno foram definitivamente incorporadas pelos órgãos de informação e segurança, com a promulgação, em dezembro de 1968 , do Al-5. ${ }^{35}$ A adoção destes preceitos fez com que muitos brasileiros fossem vistos como "inimigos de guerra", por se colocarem contra o regime. Segundo essa doutrina, pelo fato de o país se encontrar em um estado de guerra generalizada, todos os meios deveriam ser utilizados contra o inimigo, inclusive ilegais. ${ }^{36}$ Desta forma, urgia a necessidade de coleta de informações dos acusados, o que justificava o aperfeiçoamento do SNI, bem como de todo o Sistema Nacional de Informações (SISNI). ${ }^{37}$

\section{A Guerrilha do Araguaia.}

Duas obras foram fundamentais para o desenvolvimento deste tópico, em razão da qualidade, atualidade e riqueza de suas fontes: o livro de Taís Morais e Eumano Silva, "Operação Araguaia - Os arquivos secretos da Guerrilha", que recebeu o Prêmio Jabuti de Reportagem no ano de 2006, e a dissertação de mestrado de Hugo Studart, "A Lei da Selva”. A primeira obra nos mostra um levantamento de arquivos secretos, ou seja, documentos produzidos por integrantes das Forças Armadas, bem como os produzidos por guerrilheiros,

34 MATHIAS, Suzeley K. A militarização da burocracia: a participação militar na administração federal das comunicações e da educação, 1963-1990. São Paulo: Editora da Unesp/Fapesp, 2003.

35 FICO, Carlos. Como eles agiam.

36 FICO, Carlos. Como eles agiam, p.76.

37 O Sistema Nacional de Informações - SISNI - consolidou-se entre 1969 a 1970 e tinha como órgão central, responsável pela supervisão, o SNI, embora os outros órgãos contassem com o mesmo valor. A comunidade abrangia todos os órgãos públicos responsáveis pela coleta e análise de informações relacionadas à segurança, para que houvesse uma colaboração mútua neste universo, ou seja, uma grande troca de papéis entre os diversos órgãos de segurança e informação. A comunidade contava com os serviços secretos das três armas - Exercito (CIE), Marinha (CENIMAR), Aeronáutica (CISA) -, o SNI, uma parte da Policia Federal, a Comissão Geral de Investigações (CGI), as divisões de informações que estavam presentes em todos os ministérios - DSI, ASI, as delegacias estaduais de Ordem Política e Social (DOPS), as segundas seções das unidades militares e, finalmente, com os serviços de informações das polícias militares.Essa integração deveu-se a necessidade vigente do momento de aperfeiçoar o sistema de segurança, sob o amparo da definição de "guerra revolucionária" presente no AI-5, passando assim, da esfera de prestar informações ao presidente da Republica a esfera que se unia a policia política, influenciando e atingindo a vida particular de cada cidadão, conforme defendido por Carlos Fico e Priscila Antunes. 
além de testemunhos, sobretudo dos moradores da região, dos sobreviventes do confronto e de seus familiares.

Studart, como descreve no livro, estabeleceu relações próximas a muitos militares tanto da ativa como da reserva, embora reconheça a dificuldade do acesso aos documentos. ${ }^{38} \mathrm{O}$ autor usa de fragmentos de textos, reportagens, livros e depoimentos, ora divulgado por jornais, ora pelo próprio $\mathrm{PCdoB}$, afim de que os militares entrevistados tivessem suas memórias reavivadas. Além disso, esses militares forneceram a Studart vários fragmentos de documentos, tais como mapas, relatórios e planos de infiltração, a exemplo de o Diário do Velho Mário, cuja autoria pertencia ao comandante-chefe das Forças Guerrilheiras, Maurício Grabois. Sendo assim, compilou tais fontes e criou o Dossiê Araguaia.

Considerando a riqueza das fontes consultadas/elaboradas, amparamos na narrativa destes autores para, na observação do cenário projetado, analisar o modus operandi desenvolvido pela comunidade de infromações.

\section{Segredo e perseguição $0^{39}$}

Em fins de 1961, quando João Goulart estava no poder, ocorreu a mais importante cisão do Partido Comunista do Brasil, até então conhecido pela sigla PC. Desde então, o partido se dividiu em duas agremiações políticas, em razão da forma diferente que os dois grupos encaravam a forma de relacionamento com o governo: enquanto a cúpula do partido, representada pelo seu então presidente Luis Carlos Prestes, insistia na via da legalização, buscando o registro do partido e até mesmo aderindo a outras siglas partidárias, a dissidência, reunida em torno do antigo dirigente João Amazonas, defendia o trabalho de base e a adoção de medidas mais violentas, como greves e boicotes. Assim, criou-se o PCB, que ficou com a insígnia, mudando seu nome para Partido Comunista Brasileiro, e o PCdoB, que manteve o título tradicional de Partido Comunista do Brasil.

Após o golpe de 1964 o PCdoB adotou uma postura ainda mais radical, pois entendia que a presença dos militares no poder não deixaria brechas para a atuação política, qualquer que fosse. Com isso, o partido assumiu definitivamente a luta armada como sua principal arma de combate ao regime..$^{40}$

38 A subtração de documentos secretos de repartições públicas se configura infração ao Regulamento Disciplinar das Forças Armadas.

39 Esta parte do texto tem como fonte principal STUDART, Hugo. A lei da selva: estratégias, imaginário e discurso dos militares sobre a guerrilha do Araguaia. São Paulo: Geração Editora, 2006; e MORAIS, Taís e SILVA, Eumano. Operação Araguaia, 2011.

40 RIDENTI, Marcelo. As esquerdas em armas contra a ditadura (1964-1974): uma bibliografia. Cadernos do Arquivo Edgar Leuenroth, Campinas, v.8, n.14/15, p. 259-295, 2001. 
Uma das regiões brasileiras onde ocorreu o maior e mais duradouro conflito envolvendo luta armada e sistema repressivo brasileiro está na confluência do sul do Pará, sul do Maranhão, norte de Goiás e nordeste do Tocantins, na área atualmente pertencente a este último, e conhecida como "Bico do Papagaio". Nela, desde muito antes de 1964, já havia se instalado a luta pela terra, com a presença de diferentes grupos étnicos e estratos, ${ }^{41}$ e ali, ainda hoje, permanece a falta de solução destes tipos de conflito. ${ }^{42}$

Iniciada em 1966, a Guerrilha do Araguaia, como ficou conhecida, foi promovida pelo Partido Comunista do Brasil e tinha como objetivo desencadear uma guerra revolucionária, a fim de derrubar o governo militar e estabelecer um governo socialista no Brasil, fomentando a revolução primeiramente na área rural e posteriormente na área urbana.

Seguindo a doutrina do partido, os guerrilheiros instalaram-se na região do rio Araguaia, de forma a se confundir com a própria população local. Com isso iniciaram o chamado trabalho de base, cujo objetivo era a conscientização sobre a exploração sofrida pelos trabalhadores, no caso específico rurais, e a adoção da luta armada como mecanismo de combate ao regime.

Para iniciar a guerrilha, entendiam aqueles jovens comunistas que além do treinamento e do apoio popular, seria por meio da instalação das guerrilhas, em lugares longínquos aos centros urbanos do país, que seria possível garantir uma vitória mais rápida e promover a adoção de um regime socialista duradouro. ${ }^{43}$ Por meio da proliferação de unidades guerrilheiras, preparadas para enfrentar o inimigo em espaços inóspitos, chegar-se-ia, portanto, ao poder, ao mesmo tempo em que, em contrapartida, eliminar-se-ia o capitalismo vigente. Essa tática de luta defendida pelo PCdoB é o que a literatura chama de "foquismo" e estes militantes seriam inspirados, principalmente, pelo sucesso das revoluções chinesa e cubana. ${ }^{44}$

No entanto, passados seis anos de sua "internação" no campo, os guerrilheiros foram descobertos, dando início os combates entre militantes do PCdoB e militares. O conjunto de combates estendeu-se até o final de 1974, quando finalmente todos os militantes comunistas foram mortos. Estima-se que haveria cerca de oitenta guerrilheiros, a grande maioria composta por ex-estudantes universitários e jovens profissionais liberais, que viam na luta armada a melhor forma de vencer o atraso do país. ${ }^{45}$ Por isso, com base na

41 ALVES, Gerson. Os posseiros e a luta pela terra no Bico do Papagaio 1964/1985: cultura e identidade. Disponível em: http://www.uel.br/grupo-pesquisa/gepal/terceirosimposio/gersonalves.pdf, acesso em 08 out. 2012.

42 www.agenciabrasil.ebc.com.br, acesso em 01 jul. 2012.

43 www.grandecomunismo.hpg.ig.com.br, acesso em 01 ago. 2012.

44 Para uma discussão mais aprofundada sobre Foquismo veja DEBRAY, Régis. A guerrilha do Che. Lisboa: Edições Populares, 1980

45 STUDART, Hugo. A lei da selva, p.70. 
teoria do foquismo, espalharam seus membros pela região do rio Araguaia, justamente na região do Bico do Papagaio. No contexto mundial representado pela Guerra Fria, o governo brasileiro temia que a área ocupada pela guerrilha fosse reconhecia por algum país do bloco socialista (a exemplo da Albânia e China) como "área liberada", ou seja, uma região que não mais pertenceria ao território brasileiro. Face a este temor, associado à definição "inimigo" que abrangia qualquer tipo de oposição, foram preparadas diversas campanhas militares para combater a guerrilha, após as quais, apenas vinte pessoas sobreviveram, e mais de cinquenta ainda são considerados desaparecidos políticos. ${ }^{46}$ Pelos cálculos do PCdoB, entretanto, teriam sido mortos ou desaparecidos 76 pessoas que atuavam na área do Araguaia, divididas entre 58 membros do partido (guerrilheiros), 17 trabalhadores rurais daquela região, e um soldado. Esses dados são corroborados por Studart. ${ }^{47}$ Tais combates perduraram três anos, e apenas no final de 1974, quando não se encontrava mais nenhum guerrilheiro na região, as Forças Armadas deram a sedição como completamente extirpada.

Como anteriormente dito, os primeiros guerrilheiros chegaram ao Araguaia em 1966, com o objetivo de criar um exército de libertação nacional nos moldes daquele feito por Mao Tse Tung na China. Por isso pensavam segundo as orientações do Partido, em criar primeiro as bases de libertação na zona rural, para depois armar a massa que comporia o exército sob o comando dos militantes guerrilheiros. Como o primeiro objetivo era conscientizar a massa e concomitantemente aprender as técnicas de guerrilha, os combates iniciarem-se efetivamente apenas depois que o foco guerrilheiro foi descoberto pelos militares, em 1972 e, portanto, já sob o governo do general Médici.

Foi durante a terceira campanha militar, conhecia como Marajoara, uma das mais organizadas e violentas empreendidas desde então, que foi possível realizar nossa análise, ${ }^{48}$ onde percebemos uma maior presença da atividade de informação, que já naquele momento, atuava por meio do SISSEGIN, o sistema de segurança organizado e regulamentado por meio das diretrizes especiais do presidente Médici no ano de 1970. Esse amparo institucional possibilitou

46 MORAIS, Taís e SILVA, Eumano. Operação Araguaia.

47 STUDART, Hugo. A lei da selva, p.255.

48 Dentre os movimentos de oposição, talvez a guerrilha do Araguaia tenha sido a mais estudada pelos brasileiros. No entanto, ainda assim, é um fenômeno pouco conhecido e cheio de controvérsias. Quiçá com o tempo e com a divulgação maior de documentos, possamos ter novos e reveladores trabalhos. Ainda assim, para uma visão mais especifica sobre a guerrilha do Araguaia, sugere-se consultar as seguintes publicações: CABRAL, Pedro Correa. Xambioá, guerrilha no Araguaia. São Paulo: Record, 1993; CAMPOS FILHO, Romualdo Pessoa. Guerrilha do Araguaia: a esquerda em armas. Goiânia: Editora da UFG, 1997; MAKLOUF, Luis. O coronel rompe o silêncio. São Paulo: Objetiva, 2004; MONTEIRO, Adalberto. (org.). Guerrilha do Araguaia: uma epopéia pela liberdade. São Paulo: Anita, 2002; MORAIS, Tais e SILVA, Eumano. Operação Araguaia; STUDART, Hugo. A lei da selva. 
mudanças táticas importantes, revelando que até mesmo a estratégia teria sido atingida.

A descoberta do foco guerrilheiro no Araguaia por parte do governo brasileiro ocorreu apenas na década de 1970, o que explica que os primeiros combates tenham se apresentado somente em 1972. Desta data até 1975, ocasião em que a guerrilha foi dada como extinta, as forças armadas promoveram três campanhas. As duas primeiras seguiram os padrões tradicionais de combate, tendo como principal força o Exército, que utilizou tropas regulares, armamentos tradicionais, e seguiu à risca as regras de combates. Já para a última campanha os relatos insistem que os serviços de informações intervieram, afastando as tropas convencionais, e impondo importantes mudanças no modus operandi, o que teria viabilizado a vitória definitiva da ditadura. Conhecida como Operação Marajoara, a terceira campanha do Araguaia utilizou as mesmas técnicas da guerrilha: os militares entraram na floresta em trajes civis, com identidade falsa, usando armas leves, sendo acompanhados pelos chamados "mateiros", habitantes locais transformados em soldados. Por isso seu conhecimento do território e de suas armadilhas eram conhecidos por estes soldados até mais do que pelos guerrilheiros ali baseados há tanto tempo. ${ }^{49}$ E também como os militantes comunistas, os militares tinham motivação ideológica, a Doutrina de Segurança Nacional, nesta época já meticulosamente desenhada e reproduzida. ${ }^{50}$ Podemos ver nas palavras de Eumano Silva e Taís Morais o que foi a Operação Marajoara:

A Operação Marajoara começou no dia 7 de outubro de 1973. Planejada pela $8^{\mathrm{a}} \mathrm{RM}$, com colaboração do $\mathrm{CIE}$, dividiu-se em duas etapas. Na primeira, as patrulhas prenderam e neutralizaram a rede de apoio aos guerrilheiros. $\mathrm{Na}$ segunda, vasculharam as áreas de depósito e homizio.[...] A Operação Marajoara foi desencadeada com menos de 300 militares. Agiram em trajes civis e com equipamentos diferentes dos usados pelas Forças Armadas. A $8^{\mathrm{a}}$ RM mandou 120 homens, o Comando e o Estado-Maior. A Brigada de Paraquedistas enviou 100 soldados, também com Comando e Estado-Maior. Do CMP, saiu um destacamento de informação baseado em Araguaína. O CIE atuou com 30 agentes. ${ }^{51}$

Para esta campanha o grupo de soldados foi dividido em dois, distantes cerca de $480 \mathrm{~km}$ entre si, instalados na região de Bacabal ao sul e, ao norte em Xambioá. Os soldados eram comandados por capitães e afastados das tropas

49 MORAIS, Taís e SILVA, Eumano. Operação Araguaia, p.25.

50 OLIVEIRA, Eliezer Rizzo. As forças armadas, p.20; e COMBLIN, Joseph. A ideologia da Segurança Nacional: o poder militar na América Latina. Rio de Janeiro: Civilização Brasileira, 1978, p.155-156.

51 MORAIS, Taís e SILVA, Eumano. Operação Araguaia, p.449. 
regulares, pois obedeciam a uma cadeia de comando paralela, tendo no seu topo o tenente-coronel Sérgio Torres, chefe da seção de operações do Centro de Informações do Exército (CIE) em Brasília, que se reportava diretamente ao chefe do $\mathrm{CIE}$, general Milton Tavares, e mais tarde, ao general Confúcio Danton de Paula Avelino. ${ }^{52}$ Durante toda a operação, Exército e Aeronáutica colaboraram especialmente por meio de seus serviços de inteligência. Já a Marinha, por sua atuação nas duas operações anteriores, teria sido afastada do cenário de combate.

E aqui começamos a observar a distinção do modus operandi do setor de informação, que passava a atuar de forma paralela á estrutura das forças armas. Apesar de as operações acontecerem na confluência de três estados, em uma região de responsabilidade de Comandos do Exército diferentes, nenhum dos comandantes foi informado da campanha que ali acontecia, na medida em que o comandante geral da operação era o próprio ministro do Exército, general Orlando Geisel. É provável que boa parte da explicação do pouco conhecimento sobre a guerrilha, especialmente sobre a Operação Marajoara, encontre-se neste comando paralelo.

Levados para Bacabal e Xambioá, a tropa era composta por 250 homens, 130 vindos de Manaus e especialistas em guerra na selva, 110 paraquedistas do Rio de Janeiro, e 10 agentes de inteligência, aos quais se somaram 35 outros. Estes últimos já estavam na região desde pelo menos a Operação Sucuri, como foi chamada a segunda campanha, e já conheciam a região, compondo o que se conhece por "mateiros". A tática adotada foi a de, assim que chegaram, prender com bastante violência os moradores locais (160 pessoas foram presas), buscando mostrar que quem mandava ali não era a guerrilha, e sim aquele novo grupo. Com isso quebraram o cordão de apoio dos guerrilheiros, conquistado ao longo dos anos em que ali haviam permanecido. ${ }^{53}$

Ainda no mesmo dia da realização das prisões foram organizados vinte grupos de 12 combatentes, somando-se a cada grupo pelo menos um major (ou capitão antigo ou tenente-coronel novo) do CIE, cujo objetivo era entrar na floresta e buscar os locais de suprimento da guerrilha, destruindo todos os armazéns. Isso obrigaria os guerrilheiros à penúria, na medida em que eram dependentes do que poderiam tirar da própria floresta, inclusive remédios e material médico. Esta foi a principal causa das doenças, como malária e febre amarela que debilitou os guerrilheiros. Desta forma, teria sido a partir do ataque à logística da guerrilha, que passaram a caçar os guerrilheiros. ${ }^{54}$

52 MORAIS, Taís e SILVA, Eumano. Operação Araguaia, p.224.

53 MORAIS, Taís e SILVA, Eumano. Operação Araguaia, p.449.

54 Dossiê Araguaia. Apud STUDART, Hugo. A lei da selva, p. 221. 
Entretanto, quando teve início a Operação Marajoara o número de guerrilheiros do PcdoB lá instalados era de apenas 56: 22 guerrilheiros no Destacamento A, 12 no o B, e 14 no o C, e, por fim, 8 em sua Comissão Militar. Mas não somente o contingente populacional era reduzido: segundo o Relatório Arroyo, 0 armamento continuava insuficiente. ${ }^{55} \mathrm{~A}$ maioria dos combatentes tinha pouca roupa bem como não possuía sapatos, a comida estava escassa e, por fim, "a guerrilha dispunha de $\mathrm{Cr} \$ 400,00$ para sustentar a luta contra o governo Médici. Era o equivalente ao soldo de um dia para os cabos que soldados que os combatiam". 56

A Operação Marajoara levou a algumas modificações da estrutura tradicional do Exército, como ao setor responsável pelas informações em campanha (o chamado E-2), que deixou de ser responsabilidade de um indivíduo, para funcionar em triunvirato. Geralmente o triunvirato funcionava com dois oficiais do CIE e um do Centro de Informações e Segurança da Aeronáutica (CISA), que passaram a trabalhar em sistema de revezamento, e que contava com agentes de informação para auxiliar os seus trabalhos. ${ }^{57}$ Também a forma de conduzir as operações de campo sofreu mudanças: a cada final de tarde, quando retornavam da mata para o QG em Bacabal e Xambioá, havia uma reunião do Estado-Maior da Operação Marajoara para avaliar os resultados do dia e planejar ações para o dia seguinte. Esses soldados eram subordinados ao Estado-Maior, instalado em Marabá, que ficou conhecida como "Casa Azul”, em razão de sua pintura. Esta propriedade pertencia ao Incra e estava localizada em uma área isolada, a beira do rio Tacaunas. Estavam autorizados a entrar Casa Azul apenas os agentes de informações, ficando excluídos os comandantes das tropas da área, independentemente da patente do comandante ser superior a dos agentes. ${ }^{58}$ Os assuntos ali tratados eram de responsabilidade direta do Centro de Informações do Exército em Brasília.

Com o encerramento do conflito do Araguaia em dezembro de $1973^{59} \mathrm{e}$ seu total extermínio em 1975, os resultados da Operação Marajoara obtida em seus três meses de vigência assim se resumem:

- reconquista da população e seu apoio;

- destruição de mais de $70 \%$ dos estoques de suprimento do inimigo;

- destruição de sua oficina de armas e impressora;

- levantamento da maior parte das áreas de homizio;

\footnotetext{
MORAIS, Taís e SILVA, Eumano. Operação Araguaia, p 451.

MORAIS, Taís e SILVA, Eumano. Operação Araguaia, p 451.

Apud STUDART, Hugo. A lei da selva, p.2216.

58 STUDART, Hugo. A lei da selva, p. 227 e 232; e MORAIS, Taís e SILVA, Eumano. Operação Araguaia, p.450.

59 www.educacao.uol.com.br/historia-brasil/guerrilha-araguaia.jhtm, acesso em 09 out. 2012.
} 
- apreensão de $30 \%$ de seu equipamento e $20 \%$ de seu armamento;

- $50 \%$ de perdas nos Comandos de Destacamentos e Grupos (incluindo 2 dos 3 Cmt Dst);

- $40 \%$ de perdas no total de combatentes do Partido e $75 \%$ de perdas nos combatentes recrutados na área. ${ }^{60}$

Vemos assim um ambiente desfavorável para a continuação do combate. As perdas de combatentes e de materiais deixavam os comunistas desgastados não apenas física, mas psicologicamente também. As atitudes dos combatentes foram observadas pelos militares ao longo da Operação Marajoara:

No início, a intenção dos inimigos era colocar em prática ações de fustigamento e emboscadas. Pretendiam desgastar as tropas, causar baixas, capturar armas e munições. Os ataques simultâneos, pelo sul e pelo norte, com o controle da rede de apoio, impediram a ação dos esquerdistas. A nova estratégia dos militares deixou os guerrilheiros na defensiva desde os primeiros dias da nova operação. Pegos de surpresa,tiveram poucas oportunidades de pôr em prática as técnicas aprendidas na selva ou na China de Mao Tsé-Tung. ${ }^{61}$

As informações sobre a Operação Marajoara são muito díspares. Entretanto podemos inferir a partir desta alteração do modus operandi da campanha no Araguaia, que a reestrutura de atuação conduziu os militares á vitoria, inclusive no que se refere ao segredo em torno de suas ações, seja em relação ao público de forma geral, seja em relação a setores diretamente relacionados ao tema, a exemplo dos comandantes de cada um dos estados, o que de alguma forma extrapola ainda mais a ideia de secretismo que guardamos em relação a estes órgãos. De acordo com o trabalho de Studart e o de Eumano Silva e Taís Morais, haveriam relatos a respeito da produção de fotos ou mutilação de dedos (ou mesmo mãos) dos guerrilheiros mortos, que teriam sido feitas justamente para facilitar a identificação futura. No entanto, todo esse material teria sido incinerado por volta de 1974, por ordem do então presidente general Ernesto Geisel, e muitas perguntas sobre o Araguaia ainda hoje, pairam no ar.

\section{Conclusões}

A cultura do segredo que envolve as questões do Estado, especialmente aquelas relativas à defesa em um Estado Democrático é, na maioria dos casos, justificável, sendo ainda mais para os operadores das ações de defesa, na

60 MORAIS, Taís e SILVA, Eumano. Operação Araguaia, p.476.

61 MORAIS, Taís e SILVA, Eumano. Operação Araguaia, p.477. 
medida em que o segredo é quem, muitas vezes, garante o afastamento das ameaças. No entanto, nem sempre o que é imprescindível para a política, vale para os operadores da defesa.

Por outro lado, o ethos militar tem seu centro de gravidade em valores como lealdade, conservação, observância das convenções, respeito à hierarquia, disciplina, ordem e controle. Ou seja, aquilo que norteia o comportamento do soldado está muito distante do que faz e deve fazer o político.

Queremos com isso dizer que, ao tomarem o Estado e ocupar seus principais postos, os militares se encontraram expostos à lógica da política que não coaduna, ao menos por hipótese, e até mesmo confronta, o ethos militar. Por isso, ao atuarem como caçadores de pessoas (capitães do mato?), agirem com violência desmedida contra a população, e pelo fato de não estarem sob o comando hierárquico - quem comandava de fato eram os E-2 -, apenas o véu do segredo poderia preservar a integridade do seu ethos. Essa é nossa hipótese para explicar, ainda que parcialmente, a intolerância castrense contra a memória histórica em torno dos acontecimentos do Araguaia. 